\title{
Performance management system and public service delivery in Nigeria: Impacts, problems, challenges and prospects
}

Author:

Augustine N. Eneanya ${ }^{1}$ (

Affiliation:

${ }^{1}$ Department of Political Science, University of Lagos, Nigeria

Corresponding author: Augustine Eneanya, austineneanya

2010@yahoo.com

Dates:

Received: 03 Oct. 2017

Accepted: 26 Apr. 2018

Published: 17 July 2018

How to cite this article:

Eneanya, A.N., 2018,

'Performance management system and public service delivery in Nigeria: Impacts, problems, challenges and prospects', Africa's Public Service Delivery and Performance Review 6(1), a201. https://doi. org/10.4102/apsdpr.v6i1.201

\section{Copyright:}

(c) 2018. The Authors. Licensee: AOSIS. This work is licensed under the Creative Commons Attribution License.

Read online:
Background: Managing workers' performance is an effective mechanism for developing both workers and organisational effectiveness. By clarifying an organisation's objectives, translating these objectives into clear individual goals and reviewing their goals regularly, performance management provides a well-structured and effective management tool for public service delivery.

Objectives: The aim of this article is to examine performance management system approaches introduced in Nigeria between 1960 and 2017 for public service delivery.

Methods: This study relied on secondary sources of data collection, such as public service reforms, textbooks, journal articles, newspapers and the Internet. Data analysis techniques adopted include content, thematic, historical and secondary data analyses.

Results: The results show the impact made and problems and challenges experienced. They include inconsistent and contradictory reforms from one regime to another, the absence of clear indices of measurement, lack of employees' engagement, the use of traditional line item and zero-based budgeting systems instead of performance-based budgeting system and incentives do not built into performance management, among others.

Conclusion: The article concludes that performance management system is yet to be entrenched in public sector management in Nigeria and recommends, among other things, that government should embark on institutional reforms to help achieve results in high-priority areas, reinforce the intent of the law to help agencies move beyond a narrow compliance culture, train public managers and administrators on fundamentals of performance management systems and the measurement of key performance indicators.

\section{Introduction}

Confronted with rising citizens' discontent over public service delivery, new technological challenges, cultural changes and globalisation, public organisations everywhere in the world are seeking means of improving their performances. Their quest is not new; rather, the concern is more with improving the performance of government. Performance management systems are effective at improving organisational performance on service delivery to citizens. Moreover, providing public services to needy citizens is an indicator to assess the sustainable delivery of efficiency and effectiveness of government. Public service delivery allows government to link with citizens in general and needy citizens in particular, so that effectiveness of public services can be qualitatively assessed.

The earliest studies on performance management in the literature were pioneered by Warren (1972), when he defined the features of performance management.

Although performance management re-emerged in the United States as a new approach in the 1980s, it was not published until 1988 (Plachy \& Plachy 1988). By the 1990s, performance management had entered the literature of human resources management in the United Kingdom as well as in the United States. However, the research project conducted by the Institute of Personnel Management provided it full recognition (Armstrong 2009), which defined it as:

a strategy that relates to every activity of the organization set in the context of its human resources policies, culture, style and communication systems. The nature of the strategy depends on the organizational context and can vary from organization to organization. (p. 22) 
This definition complied with most textbook definitions in contemporary performance management literature.

The purpose of this article is to examine the performance management system in Nigeria between 1960 and 2017 and the mechanism adopted for quality service delivery in Nigeria. The specific objectives are to:

- examine the performance management systems adopted for public service delivery between 1960 and 2017;

- identify and explain the impact, problems and challenges of performance management systems in public service delivery between 1960 and 2017;

- suggest solutions or the way forward to improve and sustain performance management systems and public service delivery in Nigeria.

Against this background, the article is structured into four parts. Part one examines the introduction, background and conceptual clarifications. Part two examines the empirical review of literature and theoretical underpinnings. Part three examines the research questions, methodology, analysis and explanations. Part four examines the impacts, problems, challenges and prospects, and concludes the article with areas for future direction.

\section{Literature review}

The concept of 'public service' can be defined as an activity of state which involves interaction with citizens as customers. Public delivery of service is an institutional arrangement that government adopts to provide public goods and services to its citizens. Hence, the choice of institutional arrangements influences the performance of public service delivery.

Basically, there are four broad types of public service delivery arrangements that governments everywhere have adopted: direct delivery of service, privatisation of service delivery, alternative service delivery (ASD) and decentralisation of service (Kettner \& Martin 1995). In direct delivery of services, the central government brings out legislation, enforces it, hires staff, puts money, produces and distributes services, either directly operating from the headquarters or through deconcentrated line agencies. It assumes full responsibility and is accountable not only for provision but also for delivering services (Kettner \& Martin 1995). In privatisation of service delivery, government transfers the delivery of public services to private companies. In such case, it assumes no responsibility, except monitoring corporations' or agencies' compliance to legal codes. For government agencies that are contracting out responsibilities for service delivery, this requires setting clear outcome-oriented objectives and defining appropriate performance measures to track success in attaining those objectives (Kettner \& Martin 1995). The third form of public service delivery is using ASD through public-private partnership arrangement. It may be in the form of 'build, own, operate and transfer (BOOT) or build, operate and transfer (BOT), or contracting out and so on' (Eneanya 2015:542). The fourth type of public service delivery arrangement is decentralisation. In this form, decentralisation is based on subsidiary principles of governance rule, where provisioning, production and delivery of services are to be devolved to the lowest tier of government (state and local units), subject to economies of scale and capacity (Kettner \& Martin 1995).

Performance has also been defined by Bates and Holton (1995) as a multi-dimensional construct, the measurement of which varies depending on a variety of factors. They also state that it is important to determine whether the measurement objective is to assess performance outcomes or behaviour. As Fletcher (2001) mentions, contextual performance deals with attributes that go beyond task competence and fosters behaviours that enhance the climate and effectiveness of the organisation. They are concerned that performance should be defined as the outcomes of works because they provide the strongest linkage to the strategic goals of the organisation, customer satisfaction and economic contributions. Guest (1996) on his part believes that performance is about outcome but that the concept should be linked to the idea of balance the scorecard.

Performance management system, therefore, connotes (Armstrong 2009):

a strategy that relates to every activity of the organization set in the context of its human resource policies, cultures, styles and communication system. The nature of the strategy depends on the organizational context and can vary from organization to organization. (p. 22)

Performance management is a 'means of getting better results from the organisation, teams and individuals within an agreed framework of planned goals, objectives and standards' (Armstrong 2009:22). Performance management is 'a range of practices an organisation engages in to enhance the performance of a target person or group with the ultimate purpose of improving organisational performance' (DeNisi 2000, pp. 250-67). Performance management is about directing and supporting employees to work as efficiently as possible in line with the needs of the organisation (Walters 1995). Performance management is a systematic way of improving business and team performance to achieve business objectives (Strebler, Bevan \& Robertson 2001). In their own contribution, DeNisi and Pritchard (2006) define performance management as a broad set of activities aimed at improving employee performance.

For the purpose of this article, the common denominators in these definitions of performance management that are adopted, include the following:

- subordinating individual objectives to corporate objectives and values;

- enabling performance expectations to be clearly defined and agreed in terms of role, responsibilities, accountabilities (expected to do), skills (expected to have) and behaviours (expected to be);

- providing opportunities for individuals to identify their own career goals and develop their skills and competencies;

- motivating people by recognising them and giving their opportunity to use their initiatives. 
Other research studies examined the impact of performance management on the overall organisation's performance or aspects of individual performance (Latham \& Locke 2002; McDonald \& Smith 1991; Wyatt 2008).

A field research showed that goal setting is an essential element in performance. A study in a logging company involving 292 supervisors established that those who set specific production goals achieved the highest productivity. A further study of 892 supervisors produced the same result (Latham \& Locke 2002). Research was also conducted by McDonald and Smith (1991) covering 437 publicly quoted US companies. The findings were that the 205 respondents with performance management as opposed to the others without performance management had higher profits, better cash flows, stronger stock performance, higher stock value and significant gains in financial performance and productivity (McDonald \& Smith 1991). Another research on the same issue found that 'review process has more engaged employees (33\% vs. 21\%) and fewer disengaged employees (12\% vs. 29\%)' (Risher 2005, pp. 18-26).

The result of these studies showed the benefits of performance management to organisations on the assumption that people are more likely to respond positively and are more likely to work to improve capabilities as they establish clear performance goals.

\section{Theoretical underpinning}

The concept of performance management has many dimensions that explain its theoretical basis and how it ought to work in practice. The dimensions provide a framework within which performance processes can be developed, operated and evaluated. The following three theories underpinning performance management are as follows: goal theory, control theory and social cognitive theory (Buchner 2007). Let us examine the theories:

\section{Goal theory}

Goal theory highlights four mechanisms that connect goals to performance outcomes:

- They direct attention to priorities.

- They stimulate effort.

- They challenge people to bring their knowledge and skills to bear to increase their chances of success.

- The more challenging the goal, the more people will be drawn on their full repertoire of skills (Latham \& Locke 1979).

This theory underpins the emphasis in performance management on setting and agreeing objectives against which performance can be measured and managed. Goals inform individuals to achieve a particular level of performance in order for them to direct and evaluate their actions (Latham \& Locke 1979).

\section{Control theory}

This theory focuses on feedback as a means of shaping behaviour. The theory argues that if people receive feedback on their behaviours, they will appreciate the discrepancy between what they are doing and what they are expected to do and take corrective action to overcome it. Feedback is recognised as a crucial part of the performance management processes because it allows the individual to track how well he or she has been doing in relation to the goal so that if necessary, adjustments in effort, direction or possibly task strategies can be made (Buchner 2007). Control theory supports the agreement of objectives, feedback and review aspects of performance management.

\section{Social cognitive theory}

Social cognitive theory is based on the central concept of self-efficacy. This suggests that what people believe that they can or cannot do, powerfully impacts on their performance. Developing and strengthening positive self-belief in employees is therefore an important performance objective (Bandura 1986; Buchner 2007). Other theoretical issues on performance management are as follows:

\section{System theory}

A system theory states that organisations should be treated as an open system that transforms inputs into outputs within the environments (external and internal) upon which they are dependent (Miller \& Rice 1967). System theory is the basis of the input-process-output-outcome model of managing performance, which assesses the entire contribution that an individual makes within the system in carrying out his or her allotted tasks, not just the outputs. Inputs comprise of the skills and knowledge that an individual brings to a job. Skills and knowledge are measured to assess development and learning needs of employees. Outcomes measure the scale of the individual's contribution to overall team, department and corporate performance, and are central to performance management. This method of managing performance is important because all the factors that influence performance, including the system and the context, can be taken into account when assessing it (Miller \& Rice 1967).

\section{Expectancy-based motivational model}

Expectancy-based motivational model is based on the belief that people allocate energy to actions in a way that will maximise their anticipated need satisfaction (DeNisi \& Pritchard 2006). The key for performance management is to ensure that evaluation and outcomes are structured so that employees will focus their actions in the ways desired by the organisation, resulting in the kind of performance that is needed and appropriate rewards. The stronger the links between each element in the motivation process, the greater will be the motivation of employers to improve their performance. The process should aim to strengthen the perceived connection between actions and outcomes (DeNisi \& Pritchard 2006). 


\section{Performance contract model}

A performance contract model is a set of reciprocal but unwritten expectations that exist between employees and employers. A performance contract is implied and inferred rather than stated and agreed. It cannot necessarily be spelt out in detail because it evolves over time. But performance management processes can be used to ensure that performance expectations are agreed and reviewed regularly. And this should contribute to the clarification of the psychological contract and the employment relationship. This article adopts the performance contract model as the framework of analysis.

\section{Methodology}

The methodology adopted qualitative research design which involves historical analysis and review of relevant literature, public service reforms, textbooks, journal articles, newspapers and the Internet. The content analysis technique was utilised to elicit key themes. Thematic and secondary data analysis techniques were utilised to answer and explain the research questions. Based on the analysis, impacts, challenges and prospects were identified and conclusions drawn.

\section{Research questions}

This article is therefore driven by three research questions:

1. What are the approaches and impacts of the performance management system and service delivery in Nigeria between 1999 and 2017?

2. What are the problems and challenges experienced in using the performance management system to deliver public services to the citizens in Nigeria?

3. What are the prospects of installing the performance management system for efficient service delivery to citizens in Nigeria?

\section{Analysis, results and discussion}

RQ1: What are the approaches and impacts of the performance management system and service delivery in Nigeria between 1960 and 2017?

\section{Bureaucratic approach from 1960 to 1999}

The public service in Nigeria is a reflection of colonial and historical experiences. The Weberian bureaucratic model was the preferred option adopted by post-independent Nigeria to develop the capacity of administrators that respond to the people's needs and fulfil their expectations, particularly with regard to the quality of public service delivery (Weber 1947). However, it is a common knowledge that the nature of organisation structure is vital to their efficiency. Traditional bureaucratic organisational structure was adopted in the management of performance in the public service for efficient service delivery.

As years rolled by, radical changes in the nature of work began to change the ways of responding to the needs and welfare of the society. One major inducement for change in post-independent Nigeria was the management of welfare activities, which had grown too costly within the context of dwindling resources. Hence, new models of administrative reforms started drifting towards reducing the cost of governance and increasing the capacity of government to deliver public goods and services for the society. This was what prompted President Olusegun Obasanjo to embark on public service reforms in 1999 for efficient service delivery.

\section{Performance management system and SERVICOM initiative approach (1999-2007)}

When President Olusegun Obasanjo was elected in 1999, he introduced performance management system as a tool of service delivery because of socio-economic, political and technological changes in the nature of work and globalisation. Hence, a study was commissioned in 2003 to review public service delivery in Nigeria. A special report titled 'Delivering Service in Nigeria: A Roadmap' was produced, and the key recommendation was for the government to embark on a service delivery programme and initiate a far-reaching transformation of the society. The SERVICOM initiative was born from the Commission's report in 2003.

SERVICOM simply refers to 'Service Compact with all Nigerians'. Its overall goal is to build a social contract with citizens by strengthening the accountability and responsiveness of government to the legitimate demands of the citizens, especially the poor. The primary aim was to refocus government on service delivery through effective implementation of 'Service Charters' and the achievement of visible improvement in service delivery. The importance of SERVICOM derives from the fact that it addresses the issue of how best the public administration system in Nigeria can best address its primary responsibility, which is the delivery of services to citizens.

The SERVICOM initiative follows underlining principles and guidelines in its approach. They include the following:

- Development of vision and mission statements capable of building consensus on a broad development strategy that states the responsibilities of critical stakeholders, and are aligned to some new ways of doing business of government.

- Institution of a sound performance management system with mechanism for raising public expectation, costeffectiveness and value for money audit.

- Perception of citizens as beneficiaries to a service delivery framework built on contracts or service charter, that confers the rights of citizens to hold public servants accountable for service they receive.

- Use of information and communication technologies (ICTs) to improve access to government services and achieve 'seamless service delivery'. that links the threetiers of government in an integrated way to meet the needs of citizens.

- A shift from 'input' process to output results involving improved standard setting and public reporting of performance using measurable indicators. 
- Improving needs identification, participatory budgeting and planning as well as introduction of stakeholders validated performance indicators.

- Restructuring or business re-engineering and deploy ASD approaches, such as outsourcing, employee takeover, management contracting, franchising, privatisation, commercialisation, public-private partnership (PPP) and agencification.

- Availability of reliable statistics and data culture.

- A system of continuous review of tasks and decisions on what skills are needed, how they can best be sourced and how available skills can be developed and retained.

- SERVICOM index for measuring service quality delivered by departments and agencies and for SERVICOM compliance Evaluation. The SERVICOM Index includes service delivery 30\%, timeliness 24\%, information $18 \%$, professionalism $16 \%$ and staff attitude 12\% (SERVICOM, 2003).

- Customer grievance redress a mechanism reinforced by the publication of performances of Ministries, Departments and Agencies (MDAs).

- Each MDA to establish SERVICOM unit and have a SERVICOM charter. Each MDA was mandated to display information on services where customers can view them.

- A SERVICOM Institute was established as a separate entity to support service improvement in MDAs, by training public servants and a running workshop, as well as ensuring that the initiatives started by SERVICOM office are sustained in future (SERVICOM, 2003).

These principles and guidelines were adopted in 2004 as part of initiatives to deliver quality service to citizens. In most MDAs, SERVICOM initiative has recorded modest achievement. Despite this modest achievement, more remains to be achieved that would sustain a performance culture in public service delivery in Nigeria. Hence, the need for another reform for service delivery became inevitable when President Jonathan succeeded President Yar'Adua, who passed on while in office.

\section{Performance contract approach (2012-2015)}

On 22 August 2012, President Jonathan introduced a performance contract to Nigerian public service as a mechanism for service delivery. A performance contract is:

an agreement between the government and Ministries, Departments and Agencies (MDAs), which establishes general goals for the latter, set targets for measuring performance and provides incentives for achieving these targets. (Eneanya 2013, p. 185)

A performance contract system is aimed at 'upgrading contract services to the citizenry through enhanced productivity, accountability and effective service delivery' (Eneanya 2013:197). In public service, it takes the form of a continuous self-renewing cycle. To demonstrate commitment to this policy thrust, the ministers were instructed that they are responsible to the cabinet. Specifically, the ministers were requested to complete mission statements and set objectives.
They were mandated to set agreed targets for a few top priorities (as initiated by the Minister of Finance) and make transparent the budget allocated to specific services and the element to be given to each frontline unit. The ministers were enjoined to overhaul radically the existing managerial system so that they support service delivery, by (SERVICOM, 2003):

- modernising strategy;

- planning and resource allocation;

- performance audit and review;

- human resources development or renewal;

- procurement and communications;

- accountability for the use of resources and delivery of results;

- establishing a more effective balance between capital and non-staffing revenue expenditure.

To expand this initiative, ministers were mandated to enter the same performance contract with permanent secretaries. On their parts, permanent secretaries would enter into a performance contract with their directors and the rank-andfile of employees. The federal government anticipated that this initiative would be extended to state and local governments in future, using an action-oriented approach to work through the complex inter-governmental tiers.

To further improve service delivery, there was reform in the ICT sector. It was established by the Federal Ministry of Communication and Technology in 2012 as National ICT Policy. This culminated in the establishment of a government services portal, with the objective of creating a single point of entry to government information and services, enhancing accountability and improving the delivery and quality of public services through technology-enabled civic engagement and transforming public administration efficiency. Information and communication technology was adopted in 'virtually every sector in Nigeria, for example, health, industry, banking, oil and gas, education, politics and governance, government ministries, Departments and Agencies' (Eneanya, 2016). This is seen as evidence of ICT-enabled government services, such as e-passport, treasury single account (TSA), biometric, driving licence, bank verification number (BVN), land management, tax management, permanent voter's card, card reader, NYSC e-registration system and geographical information system (GIS). Information and communication technology has facilitated 'cross-industry linkages, efficiency and productivity, making the banking oil and gas and manufacturing industries in the country so heavily reliant on it for growth' (Ashike 2015:12).

\section{Efficiency unit approach (2015-2018)}

President Buhari established an efficiency unit in the Federal Ministry of Finance in 2015. This was aimed at eliminating wastes and inefficiencies. An efficiency unit is a comprehensive public sector reform initiative whose mandate goes beyond merely regulating government procurement processes. It reviews the internal mechanisms of government recurrent expenditure, work and procurement processes as well as 
practices in the public sector which promote or support wastage and inefficiency in MDAs. An efficiency unit is not a procurement regulatory agency. Its broad objective is to entrench a new culture of service delivery that promotes efficiency, value for money, prudence and integrity in the public service (Ashike 2015). It offers a participatory and cooperative platform for MDAs to accept and institutionalise a culture of efficiency across board as part of the overall attitudinal change needed to move the country forward, particularly in this period where government resources are not only lean but also under pressure because of economic recession (Ashike 2015).

The efficiency unit's mandate is clear. It includes:

reviewing government spending pattern using data from budget Implementation Report and other sources and working closely with MDAs to review work and procurement processes for specific Expenditure lines, while agreeing changes or process improvements to reduce wastages and make savings (Ashike 2015:14)

\section{Problems and challenges of performance management and service delivery in public service in Nigeria}

RQ2: What are the problems and challenges experienced by Federal Public Service in using performance management system to deliver public services to the citizens in Nigeria?

\section{- The SERVICOM initiative}

The SERVICOM initiative was a very ambitious programme and has recorded modest achievements. However, many flaws surfaced in the use of this approach. In the SERVICOM approach, the following problems were observed.

Firstly, although all MDAs have 'service charter', a few incorporated service standards. There was little evidence at the federal level that they were actively implemented at local levels, where it is more relevant to the citizens. Many MDAs display the SERVICOM charter as symbolic compliance but do not enforce defaulters and remedy grievances complained by citizens.

Secondly, it has been observed that very few MDAs' charters incorporate service standards and targets against which performance can be measured. Where they exist, there is little evidence that they are being monitored. The SERVICOM index established for measuring service delivery by MDAs are quite abstract. They should be defined in terms of ranges or categories to help interpret the practical meaning of different scale values (Olaopa 2010).

Thirdly, the impact of SERVICOM is limited because its primary focus is at the federal level, whereas the delivery of pro-poor services is the responsibility of state and local governments.

Fourthly, there is a low level of citizens' awareness of SERVICOM, partly because of its limitation to the federal level and public enlightenment awareness activities are limited.
Finally, the government budgeting system has not aligned with the performance management system. The government's budgeting system has been traditional a line item budgeting instead of establishing performance budgeting system.

\section{- Performance contract}

In the performance contract, performance measurement does not include the participation of citizens. In addition, there is no statement of reprisal for those who fail to meet performance measurement criteria. Citizens' engagement is excluded from government's reform agenda on performance contract.

Secondly, since the signing of the performance contract with ministers and permanent secretaries, there is no evidence of rank-and-file contract with permanent secretaries. The performance contract as it stood was simply President Jonathan's contract with his ministers and not popular documents that make citizens as participants.

Thirdly, there is no policy framework that provides a roadmap to the implementation of the performance contract. It should have been anchored on a clear policy that are actively monitored and implemented on a wide scale. Related to this was the absence of quantified standards and targets against which performance can be measured.

Fourthly, it is also doubtful if performance contract has actually impacted on the culture of accountability and responsiveness in public sector management, in view of cases of political and administrative corruption in the service and non-introduction of performance budgeting, which could have provided a direct link between services to be delivered and budgets.

Fifthly, many MDAs have problems of maintaining proper data (information). The data used in the performance measurement system come from a wide variety of sources, and this has implications regarding the cost and effort of data collection and processing as well as quality and appropriateness.

Sixthly, although the purpose of the performance measurement system is to help improve performance through influencing decisions, they cannot be expected to control or dictate what those decisions will be. At the lower management levels, they can be ignored and will not automatically be used (Poister 2003:19). For a performance measurement system to contribute to improved performance, it must be utilised to manage agencies and programmes more effectively.

Seventhly, a performance contract measurement for productionoriented agencies will often be relatively straight forward, but more difficult or tedious at best in agencies, whose activities admittedly have only very indirect connections to the desired results. For example, policy-oriented and support services functional units, such as planning agencies, research institutes, evaluation offices and personnel services, can be difficult to incorporate in performance measurement systems. Outcome measures for these functions are not usually available. 
Eighthly, citizens are not located in the performance contract initiative. Targets and performance set for ministers and permanent secretaries were not anchored in medium-term expenditure framework and medium-term sector strategies. So, they are not reflected in the annual budget as benchmark for assessment by citizens.

Finally, the government neglected performance budgeting but still continued with a traditional line item budgeting system which does not align with performance management techniques.

\section{- Efficiency unit}

The efficiency unit newly established in the Ministry of Finance is too centralised to be efficient. It contradicts previous reforms, such as SERVICOM and performance contract that are citizens oriented.

Secondly, the desire to reduce the bureaucratic bottleneck in government business has been frustrated by the establishment and location of an efficiency unit in the Ministry of Finance alone. In other words, all MDAs would be responsible to the Minister of Finance in eliminating wastes and inefficiencies.

Finally, the efficiency unit initiative has not been decentralised to other MDAs. The introduction of zero-based budgeting, attempts to erode the gains of SERVICOM and performance contacts in terms of citizens' engagement or participation in quality service delivery.

\section{Challenges of a performance management system and service delivery}

- Conceptual flaws: The government performance management system suffers from serious conceptual flaws that have regularly proven to be fatal. For example, often there are no consequences for good or bad performance in government. Thus, even a good performance measurement system is a waste of time. In addition, performance measurement systems in government lack (1) upfront prioritisation of goals and objectives, (2) upfront agreement on how to judge deviation from targets and (3) focus on the whole organisation.

- Lack of an incentive system: Performance measurement is merely the starting point for performance management. We need to assign clear upfront accountability for results and design an incentive system that links to those results. Unfortunately, government continues to believe that performance measurement is the same as performance management. The incentive system is not linked to results. There is no clear assignment of responsibilities and most performance measurement systems remain an academic exercise.

- Lack of agreement on how to measure deviation from targets: Most government documents continue to use single point targets as measures of success. In the absence of an exante agreement on measuring deviations from the target, evaluators have a huge subjective power over 'evaluates'. This lack of upfront agreement on how to evaluate derivations from targets is another flaw.
- Lack of prioritisation of objectives and key performance indicators: Too often, measurement systems list a number of important objectives and corresponding key performance indicators (KPIs) without prioritising them. Lack of upfront prioritisation of objectives and targets constitutes the second fatal flaw.

- Lack of comprehensive evaluation of organisational performance: Most performance measurement efforts in governments are partial and not comprehensive. They focus on a project, a policy or a few selected government departments. For sustainable change in behaviour, a comprehensive, holistic approach is a necessity. It is also worth remembering that accountability trickles down and never trickles up. Holding the department responsible is unlikely to make the whole responsible, whereas holding the whole organisation responsible will ensure that all departments are also accountable. Thus, performance measurement of only a part of the whole organisation is the fourth and final fatal flaw that stymies most performance management initiatives in governments.

- There is complexity both in the outcomes we seek to deliver and the systems we operate.

\section{Prospects of installing an effective performance management system and public service delivery in Nigeria}

RQ3: What are the prospects of installing effective performance management system for service delivery in Nigeria?

It is clear from these challenges that much remains to be done to make a performance management system a model for public service delivery in Nigeria. The question at this point is not whether to measure performance in service delivery, but rather how to design and implement measurement systems most effectively. That is, how to design overall systems to serve different purposes; how to identify the aspects of performance that should be tracked; how to tie performance measures to goals and objectives; how to manage data collection and processing; how to analyse and present performance data to their intended audiences; and how to ensure that performance measures will be used effectively to inform decisions and enhance performance. The following recommendations would assist to install a effective performance management system for public service delivery in Nigeria:

- Public managers or administrators in MDAs need to learn more about how to do performance measurement. Performance measurement systems come in all shapes and sizes, from those that monitor detailed indicators of a production process or service delivery operation within one particular agency every week to other that track a few global measures for an entire state or the nation as a whole on an annual basis. Some performance measurement systems are intended to focus primarily on efficiency and productivity within work units, whereas others are designed for public programmes. Others serve to track the quality of the services provided by an agency and the extent to which clients are satisfied with these services. 
Therefore, public managers or administrators in MDAs at the federal, state and local government levels should learn about performance measurement systems and tailor their performance measurements to the specific purpose for which the particular system is being designed and to the programme or agency whose performance is being measured.

- As service delivery is the focus of a performance management system, there is the need for a process of training needs identification and general capacity development for public managers or administrators in MDAs.

- There should be a process of re-engineering or restructuring of the institutions or agencies in terms of policies, efficient systems, processes, organisational development, deployment of technology, infrastructure and resources to enhance institutional improvement.

- Citizens' engagement in performance management and service delivery should be entrenched. There is need to build a service delivery framework on contracts or service charter that confers rights to citizens. This would guarantee the right of citizens to hold public servants accountable for the service they receive. There should be a culture of service that puts the citizens first. Citizen should be engaged to monitor services through ICTs at the sub-national level. This approach combines top-down performance management systems with institutionalised channels for citizens to participate in identifying service delivery needs and strongly relies on ICTs for handling complaints and managing assignment tasks across agencies. Linkage centres' intake requires complaints from citizens and assigns them to corresponding agencies.

- There is need to introduce performance budgeting which could provide a direct link between services to be delivered and budgets. In performance budgeting process output, efficiency and effectiveness measures are included to show relevant information, especially where decisionmakers are looking for links to actual funds. Taking output, outcomes and efficiency measures together gives policy-makers a full view of activities completed, the cost and value of the outputs and outcomes, and what has actually been accomplished with the actual expenditures. In this vein, incorporating performance measures in the budgetary process is important for identifying the relative efficiency of services.

- To advance and expand the practice of performance management at federal, state and local government levels, the following techniques should also be utilised:

- leverage the performance framework by undertaking institutional reforms to help achieve results in highpriority areas;

- reinforce the intent of the law to help agencies move beyond a narrow compliance culture;

- train public managers and administrators on fundamentals of performance management systems and measurement of key performance indicators;

- motivate public managers and administrators with good salaries and incentives;
- build and grow the performance community to include programme and performance staff throughout agencies;

- provide services and support that enable partners in agencies to become advocates, champions and coaches in their own organisations;

- establish comprehensive monitoring and evaluation machinery.

- These suggestions would lead to better outcome in the form of more compliance, results-oriented candour and transparency.

\section{Areas of future research}

Future research direction should attempt to investigate how ICT platforms should be used through institutional frameworks at nation and sub-national levels to engage citizens in identifying service delivery needs, assign task across agencies and handle complaints. Linkage centres should be established using mobile applications to intake requests and complaints from citizens. This will boost citizens' satisfaction and restore confidence in government service delivery.

Another area of research direction is how to promote a performance culture in public service at the federal, state and local government levels in terms of a healthy attitude towards risk, positive ownership spirit, accountability for results in order to build citizen-oriented quality service delivery.

\section{Conclusion}

As the quality service revolution has swept through the public management landscape, performance management processes have become means of providing a more integrated quality service in the public service. Now, more than ever, public managers or administrators in public service are challenged to improve the quality of the services they deliver as well as increase customers' satisfaction with those services. From a performance measurement perspective, this means they must track indicators of the quality of inputs and especially of the outputs produced. Indicators of quality service delivery are often viewed as complementary performance measures and incorporated in the same reporting systems. Thus, the overall aim of quality service delivery is to improve citizen's demands and needs. So, performance measurement systems help to track feedback from customers about how they were treated by service delivery processes. Such indicators focus on detailed individual parts of the process, and collectively, they can paint a composite picture of the citizens' perceptions of the quality of service they received. A properly designed performance management system as recommended would lead to a better outcome, promote compliance and performance culture and enhance citizen-oriented quality service delivery.

A performance management system is yet to be established in Nigeria because of regime change. Every regime has its focus. From 1960 to 1999 Nigeria entrenched in bureaucratic 
model. This model was inherited from colonial masters and became the framework of service delivery to citizens. The endless delay and inefficiency in service delivery and lack of accountability to citizens made President Olusegun Obasanjo to introduce SERVICOM initiative, 1999-2007. This would make public servants accountable for their service delivery lapses to citizens. President Goodluck Jonathan's regime introduced the performance contract model between 2012 and 2015. There were no institutional reforms or capacity building of public officials to implement it and entrench the model on a solid foundation. Hence, President Mohammed Buhari introduced an efficient unit and focused on anticorruption drives and security. From all these conceptual flaws, it is right to conclude that performance management system was not firmly established in Nigeria because of various challenges, such as a lack of incentives and rewards to public servants, no institutional reforms, a lack of training for officials meant to implement it and no key performance indicators to evaluate results. Despite these challenges, a performance management system has good prospect in Nigeria. What it requires is for government to display political will and conduct institutional reforms at the federal, state and local government levels; train public officials; motivate public managers with good salaries and incentives; and establish citizens' rights that would make them question the inefficiency of public managers and administrators in service delivery.

\section{Acknowledgements Competing interests}

The author declares that he has no financial or personal relationships which may have inappropriately influenced him in writing this article.

\section{References}

Armstrong, M., 2009, Handbook of performance management, 4th edn., Kogan Page, London.

Armstrong, M., 2009, 'Performance management in the UK: An analysis of the issues' in IPM, Handbook of Performance Management Institute of Personnel Management (This title must be in italics), p. 23, Kogan Page, London.

Ashike, M., 2015, 'Efficient Unit Plans to eliminate wastes, inefficiency', viewed on December 8, 2015, p.12 from www.businessdayonline.com
Bandura, A., 1986, Social boundaries of thought and action, Prentice-Hall, Englewood Cliffs, New Jersey.

Bates, R.A. \& Holton, E.F., 1995, 'Computerized performance monitoring: A review of human resource issues', Human Resource Management Review 5, 267-288.

Buchner, T.W., 2007, 'Performance management theory: A look from the performer's perspective with implications for HRD', Human Resource Development International 10(1), 59-73. https://doi.org/10.1080/13678860601170294

DeNisi, A.S., 2000, 'Performance appraisal and performance management: A multi level analysis', in K.J. Klein and S.W.J. Kozloroski (eds.), Multilevel theory, research and methods in organizations, pp. 250-67, Jossey-Bass, San Francisco, CA.

DeNisi, A.S. \& Pritchard, R.D., 2006, 'Performance appraisal, performance management and improving individual performance: A motivational framework', Management and Organization Review 2(2), 253-277. https://doi. org/10.1111/j.1740-8784.2006.00042.x

Eneanya, A.N., 2013, Managing personnel in public sector, Ibadan University Press.

Eneanya, A.N., 2015, Theory and practice of public administration, University Press PLC, Ibadan.

Fletcher, C., 2001, 'Performance appraisal and management: The developing research agenda', Journal of Occupational and Organizational Psychology 74(4), 473-487. https://doi.org/10.1348/096317901167488

Guest, D.E., (ed.), 1996, 'The management of performance', in Address to the Annual Conference of the Institute of Personnel and Development, October, pp. 1-3, Harrogate.

Kettner, P. \& Martin, L., 1995, 'Performance contracting in the human services: An initial assessment', Administration in Social Work 19(2), 47-61. https://doi. org/10.1300/J147v19n02_03

Latham, G.P. \& Locke, E.A., 1979, Goal Setting: a motivational technique that works, Organizational Dynamics, Autumn, pp. 442-47.

Latham, G.P. \& Locke, E.A., 2002, 'Building a practical useful theory of goal - Setting and task motivation', American Psychologist 57(19), 705-717. https://doi. org/10.1037/0003-066X.57.9.705

McDonald, D. \& Smith, A., 1991, 'A proven connection; performance management and business - Results', Compensation and Benefits Review, January-February, pp. 59-64.

Miller, E. \& Rice, A., 1967, Systems of organization, Tavistock, London.

Olaopa, T., 2010, Public service reforms in Africa, University Press Plc, Ibadan.

Plachy, R.J. \& Plachy, S.J., 1988, Getting results from your performance management and appraisal system, AMACOM, New York.

Poister, T.H., 2003, Measuring performance on public and non-profit organisations, Jossey-Bass, San Francisco, CA.

Risher, H., 2005, 'Re-focusing performance management', Compensation \& Benefits Review, Octoberedition, pp.18-26. https://doi.org/10.1177/088636870503700601

SERVICOM Charter 2003. Available at servenigeria.co

Strebler, M.T., Bevan, S. \& Robertson, D., 2001, Performance review: Balancing objective and content, Institute of Employment Studies, Brighton.

Walters, M., 1995, 'Developing organizational measures', in M. Walters (ed.), Performance management handbook, Institute Personnel and Development, London.

Warren, M., 1972, 'Performance management: A substitute for supervision', Management Review, October edition, pp. 28-42.

Weber, M., 1947, The theory of social and economic organization, transl. A.M. Hederson \& T. Parson, Free Press, New York.

Wyatt, W., 2008, cited in M. Armstrong, 2009, Handbook of performance management, Kogan Page, New York. 